\title{
Paysage urbain et nationalisme dans les enclaves espagnoles de Ceuta et Melilla
}

\author{
Alicia Fernández García
}

\section{(2) OpenEdition}

Journals

\section{Édition électronique}

URL : http://journals.openedition.org/agedor/1365

DOI : 10.4000/agedor.1365

ISSN : 2104-3353

Éditeur

Laboratoire LISAA

\section{Référence électronique}

Alicia Fernández García, « Paysage urbain et nationalisme dans les enclaves espagnoles de Ceuta et Melilla », L'Âge d'or [En ligne], 10 | 2017, mis en ligne le 08 janvier 2019, consulté le 20 avril 2019. URL http://journals.openedition.org/agedor/1365; DOI : 10.4000/agedor.1365

Ce document a été généré automatiquement le 20 avril 2019.

L'Âge d'or. Images dans le monde ibérique et ibéricoaméricain 


\title{
Paysage urbain et nationalisme dans les enclaves espagnoles de Ceuta et Melilla
}

\author{
Alicia Fernández García
}

1 Depuis l'instauration du protectorat espagnol au Maroc en 1912 et jusqu'à la mort de Franco en 1975, les villes de Ceuta et Melilla ont été considérées par l'État espagnol comme deux «Plazas de Soberanía », à savoir deux territoires militarisés dirigés par des gouverneurs issus de l'armée. Avec le retour à la démocratie, elles furent exclues du cadre autonomique espagnol, ce qui les plongea dans un statu quo qui dura jusqu'en 1995, année où elles obtinrent le statut de "villes autonomiques " possédant alors un régime local propre avec quelques particularités autonomiques. L'abandon dont elles ont souvent fait l'objet par l'État central et les nombreuses situations au cours desquelles elles ont failli être rendues au Maroc prouvent que les dirigeants politiques espagnols n'ont pas toujours considéré ces territoires comme des parties intégrantes de l'Espagne. L'indépendance du Maroc en 1956 et son acharnement pour récupérer ces territoires incitèrent les autorités à renforcer leur « españolidad », leur « espagnolité » ou caractère espagnol. Le régime franquiste, dont le pouvoir et l'idéologie ont été imposés par les armes, enclencha cette entreprise de «reconstitution historique» dans le but de légitimer une présence espagnole séculaire. Cependant, c'est durant l'ère démocratique que la reconstitution historique des villes est devenue une priorité politique locale, en cherchant à ancrer leur souveraineté espagnole, à vanter leur patriotisme et à dater leurs origines latines le plus loin possible dans l'histoire.

2 Compte tenu de cette quête acharnée des origines, cet article propose d'étudier le marquage territorial du nationalisme espagnol dans le paysage urbain de Ceuta et Melilla. En raison de leur ténacité et de leur diversité, les traces iconographiques et textuelles du nationalisme espagnol à Ceuta et Melilla saturent l'espace public et s'imposent comme un élément incontournable du paysage urbain. Partant de cet intérêt pour l'iconographie du nationalisme espagnol à Ceuta et Melilla, nous analyserons dans un premier temps la reconstruction historique des villes à travers la création de mythes originaux aujourd'hui 
présents dans leur espace urbain. Ensuite, nous étudierons comment les lieux de mémoire et l'iconographie nationaliste ont forgé la transmission d'un idéal national tout en assurant sa visibilité dans le paysage urbain et sa transmission générationnelle. Enfin, la dernière partie s'intéressera au calendrier mémoriel de ces villes, dont l'analyse dévoilera comment les fêtes, les cérémonies et les commémorations militaires et religieuses perpétuent aujourd'hui encore la mémoire du nationalisme espagnol.

\section{La reconstruction historique de l'espace urbain : création de mythes et de référents historiques}

3 L'histoire joue un rôle clé dans la construction des identités nationales, donnant naissance à ce que l'on appelle les politiques de la mémoire ${ }^{1}$. Ainsi, l'historiographie nationaliste procède généralement à la sélection de faits susceptibles d'élaborer un grand récit national, en mettant en avant des dates, des événements et des acteurs censés représenter l'appartenance d'un peuple et de son territoire ${ }^{2}$. À Ceuta et Melilla, les autorités locales ont procédé à une instrumentalisation de la nomenclature urbaine afin de transmettre une série de valeurs dites «nationales » aux habitants. Le paysage urbain de Ceuta a connu, depuis quelques années, la multiplication de monuments et de statues qui proposent un parcours historique de la ville par le biais de personnalités emblématiques, de philosophes, de géographes, etc., liées à celle-ci par leurs écrits ou leurs origines. Ce retour aux souches permet de reconstruire l'histoire locale en légitimant l'existence séculaire de la ville et ses liens avec le monde gréco-romain. Cette reconstruction de l'histoire de Ceuta trouve sa première expression dans la valeur symbolique octroyée à son environnement naturel et notamment au promontoire de 839 mètres connu comme "La mujer muerta" en raison de sa silhouette. Selon l'interprétation donnée par l'histoire locale, il s'agirait de l'une des colonnes d'Hercule, l'autre se trouvant sur le rocher de Gibraltar ${ }^{3}$. Toutefois, pour les sources arabes, il s'agirait de l'image gisante du général Musa Ibn Nusair, qui commanda l'invasion musulmane de la péninsule Ibérique en 711.

Dans la mise en scène architecturale de l'histoire de Ceuta, les liens entre la mythologie et la ville ne s'arrêtent pas à ce promontoire. La séparation du détroit de Gibraltar par les deux colonnes d'Hercule constitue pour la ville un mythe fondateur. Ces deux colonnes reliées entre elles par les mots "Non Plus Ultra", symbolisent les deux extrêmes du monde connu par les Grecs : elles sont la représentation d'Abyla, nom mythologique de Ceuta, et de Calpe, à savoir Gibraltar ${ }^{4}$. Si l'Hercule dressé sur la Place de la Constitution de la ville tâche de séparer ces deux colonnes et, avec ce geste, les deux mondes, l'Occident et l'Orient, en revanche, la sculpture d'Hercule située au port les embrasse. Cette image d'un Hercule unificateur et séparateur à la fois contient un symbolisme spécial à Ceuta qui, malgré sa situation géographique excentrée sur le continent africain, se veut partie intégrante du monde occidental. La fonctionnalité de cet ensemble monumental consacré à Hercules est donc de témoigner de l'ancrage ancien de la ville qui puiserait ses origines dans le monde antique.

5 Les bustes de géographes et d'historiens dont les écrits ont fait allusion d'une manière ou d'une autre à Ceuta (Abyla) participent à cette recherche de légitimité historique. Ainsi, sous le portrait du géographe Estrabon, on apprend l'étymologie du nom de Ceuta et l'histoire de sa fondation: "Partiendo de Lixus y navegando hacia el mar mediterráneo, se 
encuentra Zelis y Tingi, luego la tumba de los siete hermanos y encima el monte llamado Abyla, poblado de fieras y cubierto de grandes árboles." Les sculptures de Pompinio Mela, géographe romain, et de Platon, philosophe grec, nourrissent également cette quête de racines liées au monde gréco-romain ${ }^{5}$. Les personnages de l'Antiquité sont ainsi récupérés avec la volonté de servir d'exemples pour le temps présent. Si ces références permettent de mettre en scène l'existence de la ville dans l'Antiquité, les portraits du géographe AlIdrisi ${ }^{6}$ et du philosophe Josef Ben Yehudá Ibn-Aknin, nés à Ceuta, témoignent de son existence durant le Moyen Âge.

6 Ces références à des personnages historiques cherchent à donner des preuves de l'hispanité de la ville depuis un temps lointain, avant même la naissance de l'Espagne moderne. Elles permettent de montrer comment, depuis un temps immémorial, Ceuta et l'Espagne auraient partagé la même histoire, ce qui permettrait d'affirmer l'« éternelle hispanité de la ville ${ }^{7}$. À cet égard, sa découverte par les Portugais en 1415 constitue l'événement historique par excellence lui permettant d'affirmer son entrée dans «l'Âge moderne $»^{8}$. L'idéalisation de cet événement s'empare du discours du chroniqueur local José Luis Gómez Barceló, pour qui la conquête portugaise constituerait un point d'inflexion historique, négligeant toute sa cruauté'. Cette période portugaise de la ville est symboliquement représentée dans l'espace urbain par les sculptures de Don Pedro de Meneses, premier gouverneur portugais de la ville ou du prince portugais, Henri le Navigateur. Ce parcours historique à travers les sculptures culmine avec une série de statues allégoriques chargées de références morales, car elles se dressent comme les représentantes des valeurs des habitants. Les allégories du travail, au commerce, à la paix propagent une certaine moralité dans le paysage urbain et accomplissent un rôle de transmission de valeurs forgées par le pouvoir en place ${ }^{10}$.

7 À Melilla, l'attachement historique à l'Espagne se fonde sur l'argument du res nullius auquel font allusion les chroniques espagnoles qui décrivent un territoire non peuplé et abandonné à l'arrivée du conquérant espagnol, don Pedro de Estopiñán. Cet argument est récupéré par l'historien local Antonio Bravo Nieto dont la description constitue un exemple de ce no man's land que veut être Melilla : "Melilla fue, en cierto sentido, como el Lejano Oeste americano, una tierra virgen en la que empezar de nuevo." ${ }^{11}$ De même, dans cette quête des origines et du legs hispanique, il est important de s'intéresser à la promotion touristique de Melilla comme «une ville moderniste». Cette nouvelle construction mémorielle s'appuie sur une argumentation historiciste dans la mesure où ce legs architectural est présenté comme le résultat du génie artistique espagnol : "un gran tesoro de la historia del arte español"12. Les guides touristiques vantent le grand apport de l'architecture moderniste à Melilla qui réside dans l'association d'un urbanisme doté d'une rationalité militaire avec les courants modernistes d'influence catalane ${ }^{13}$. Le modernisme sert ainsi à renforcer l'argument historique de l'hispanité à tel point que Melilla, avec ses quelques bâtiments d'époque, se revendique comme étant la deuxième ville «moderniste» de l'Espagne après Barcelone ${ }^{14}$. Mais l'éclat de ces constructions modernistes ne saurait masquer une autre réalité : celle d'une ville obsédée par sa défense comme le montrent l'ampleur de son architecture militaire et l'étendue de ses murailles ${ }^{15}$. 


\section{Iconographie nationaliste et lieux de mémoire à Ceuta et Melilla}

8 L'iconographie, entendue comme l'ensemble des images ou des représentations plastiques autour d'un même sujet, et la toponymie, qui fait référence à l'usage des noms au-delà de leurs fonctionnalités techniques, peuvent être des outils au service de l'instrumentalisation politique. Une instrumentalité qui permet à ces éléments de jouer un rôle central dans l'affirmation d'un pouvoir et de devenir de véritables protagonistes du paysage urbain ${ }^{16}$. Pendant des décennies, l'iconographie et l'architecture ont été au service de l'Église, de la Monarchie et de la bourgeoisie, et ces trois pouvoirs se sont servis de l'art pour leur glorification et leur auto-affirmation ${ }^{17}$. Le pouvoir religieux a ainsi souvent conçu d'imposants monuments architecturaux pour manifester son autorité et sa suprématie et pour susciter le respect, l'admiration voire la peur. De même, le pouvoir politique a vite compris la valeur symbolique du patrimoine et pour cela, il a eu recours à la représentation d'épisodes et de héros des guerres afin de les transformer en icônes d'une nouvelle identité nationale ${ }^{18}$.

9 Dans les villes de Ceuta et Melilla, le développement de l'iconographie et de la toponymie a été étroitement lié au pouvoir religieux, comme le montre la succession d'églises ou d'images de vierges, et au pouvoir militaire, comme en témoignent l'image de Franco, le nombre de rues consacrées à des phalangistes et chefs militaires, les monuments en hommage aux différents régiments militaires et aux batailles de la guerre d'Afrique. Ces « lieux de mémoire » mais aussi le recours à des symboles nationalistes affichés sur des sculptures, plaques et portraits visent à reconstruire un paysage urbain où l'on façonne les souvenirs des guerres et la mémoire des vainqueurs. Comme les cathédrales ou les images grandioses des vierges qui ornent les villes et l'intérieur de leurs églises, ces nouvelles sculptures dominent le paysage urbain proposant une interprétation de l'histoire avec laquelle les habitants doivent cohabiter ${ }^{19}$. Le paysage urbain se présente ainsi comme un espace anthropologique, défini par son caractère identitaire, où les habitants peuvent se reconnaitre et partager un sentiment d'appartenance au sein de leur environnement ${ }^{20}$. De même, le concept de «lieux de mémoire ", défini par Pierre Nora, fait référence à ces symboles (drapeaux, hymnes, blasons) ou à ces monuments (statues, plaques, etc.) où la mémoire nationale se dresse en s'immortalisant. Pour Pierre Nora, les lieux de mémoire sont intimement liés au nationalisme et à la mémoire nationale, en ce qu'ils permettent à un peuple de proposer un récit commun, d'établir un lien symbolique entre le passé et le présent, et de renforcer le sentiment d'appartenance grâce à des célébrations et des rites partagés ${ }^{21}$. La portée de ces lieux de mémoire et leur présence dans le paysage urbain seront les enjeux traités dans cette partie.

\section{Les monuments du nationalisme espagnol}

10 À Ceuta, l'architecture commémorative des réussites militaires, si chère à cette ville, trouve son meilleur exemple dans le monument consacré aux héros de la guerre d'Afrique (1859-1860)22. Une guerre glorifiée dans la ville mais qui pourtant alimente toujours dans l'imaginaire collectif espagnol un souvenir amer ${ }^{23}$. Une ardeur patriotique diffusée dans la grande quantité de chroniques journalistiques, de récits, de chansons, de monuments que cette guerre dite de "régénération nationale " suscita et qui se transforma en 
tonalité de base ${ }^{24}$. Ainsi, les mots de Núñez de Arce, envoyé spécial à Melilla du journal La Iberia, manifestent bien ce climat d'euphorie patriotique qui accompagna cette guerre : "El cielo me ha proporcionado la dicha de ser testigo de la empresa más grande, más heroica que ha acometido y llevado a feliz término nuestra querida España desde la gloriosa guerra de la Independencia." ${ }^{25}$ En 1890, les autorités militaires de Ceuta décidèrent de dresser un monument public pour commémorer cette guerre et faire honneur aux combattants morts afin de les transformer en martyrs de la nation ${ }^{26}$. Le lieu choisi fut l'actuelle Place de la Constitution, centre névralgique de la ville où se trouvent les sièges des trois pouvoirs locaux : la mairie, berceau du pouvoir civil, le bureau du commandant, siège du pouvoir militaire et l'Église, pilier du pouvoir religieux.

Image 1. Monument commémoratif de la Guerre d'Afrique (1859-1860)

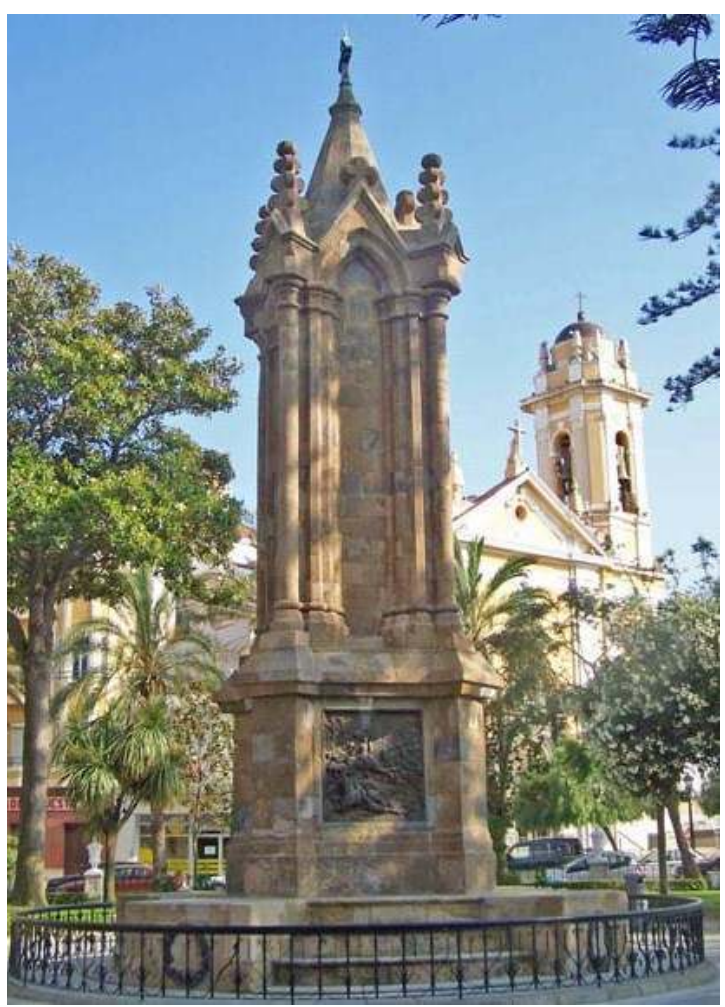

Source : Alicia Fernández García, Vivre ensemble. Conflit et cohabitation à Ceuta et Melilla, Paris L'Harmattan, 2017, p. 274.

11 Cet ensemble monumental met en évidence une prise de position très claire en faveur de la sacralisation historique des héros et des martyrs de cette première guerre d'Afrique. À ce sujet, il est très important de s'intéresser à ses bas-reliefs car ils sont des représentations allégoriques des généraux espagnols Prim et O’Donnell, drapeau espagnol à la main. En revanche, les combattants marocains, toujours très nombreux, apparaissent dans une attitude d'échec. Sa double fonctionnalité, commémorative et funéraire à la fois, illustre les deux clés de lecture de ce mausolée ${ }^{27}$. La première lecture est celle de l'immortalité religieuse des soldats espagnols morts au combat en raison de leur foi et de leur lutte contre l'infidèle musulman. L'immortalité historique et nationale constitue le deuxième niveau de lecture du monument, une postérité obtenue grâce à leur héroïsme pour avoir vaincu les ennemis de la patrie. 
12 À Melilla, on trouve également un Panthéon consacré aux héros des campagnes d'Afrique, construit afin d'immortaliser les acteurs de la lutte contre l'ennemi marocain. Ce contexte guerrier est devenu une occasion unique pour consolider le lien existant entre les principes défendus par les armes et un certain nombre de valeurs "nationales » considérées comme menacées par l'adversaire du Maroc. Comme l'affirme Núñez Seixas, les guerres possèdent un fort effet « nationalisateur » pour les sociétés car elles stimulent la cohésion sociale du groupe mais transforment aussi l'Autre en "contraimagen necesaria para consolidar una imagen propia del yo nacional" 28 . En effet, pour les autorités des villes, ce Panthéon sert à rendre hommage, mais il se veut aussi l'expression la plus accomplie du patriotisme: "dar una respuesta a la sensibilidad suscitada en los españoles por el triste acontecimiento del Barranco del Lobo"29. La terminologie employée sur les nombreuses plaques commémoratives illustre le travail du nationalisme espagnol en faveur d'une mémoire simplificatrice réduite au binôme civilisation chrétienne versus barbarie maure : "Paz y gloria eterna a aquellos que se sacrificaron por la Civilización, por Dios y por España." Ce binôme se nourrit en effet d'une histoire singulière faite d'un antagonisme volontairement conçu entre la patrie espagnole et le voisin marocain. Ce Panthéon apparaît ainsi comme l'incarnation du patriotisme grâce à la conversion des morts en héros dont le souvenir s'avère essentiel pour forger l'identité nationale, légitimer le nouveau pouvoir et encourager les futurs combattants ${ }^{30}$.

Image 2. Panthéon des soldats morts pendant les Campagnes d'Afrique

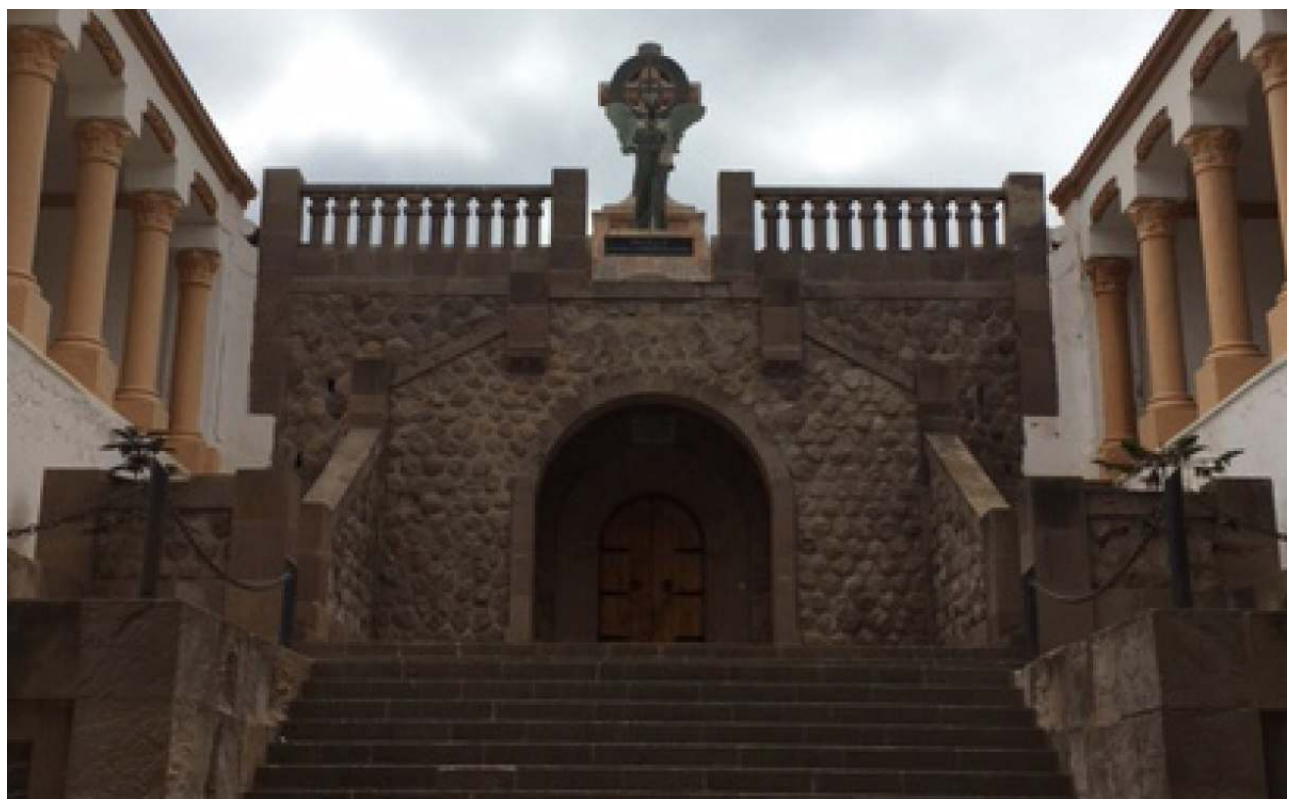

Source : Galerie photographique personnelle

Le monument dédié aux «Héros de Taxdirt» à Melilla ${ }^{31}$ fait également partie de l'architecture commémorative des soldats morts pendant la guerre d'Afrique. Il se trouve derrière le bureau central du commandement de l'armée, sur la place Pedro Segura. Son exposition publique permet selon certains habitants que "toda la ciudad pueda recordar esta historia cargada de heroísmo" 32 . "Taxdirt " se veut un exemple de patriotisme mais aussi un éloge funèbre à ces soldats espagnols qui trouvèrent la mort le 20 septembre 1909 au cours d'une attaque contre les Kabyles rifains. Tant les monuments dédiés aux 
soldats morts pendant les campagnes d'Afrique que la représentation des martyrs de la nation sont largement présents dans le paysage urbain de Ceuta et Melilla.

Image 3. Monument aux héros de Taxdirt

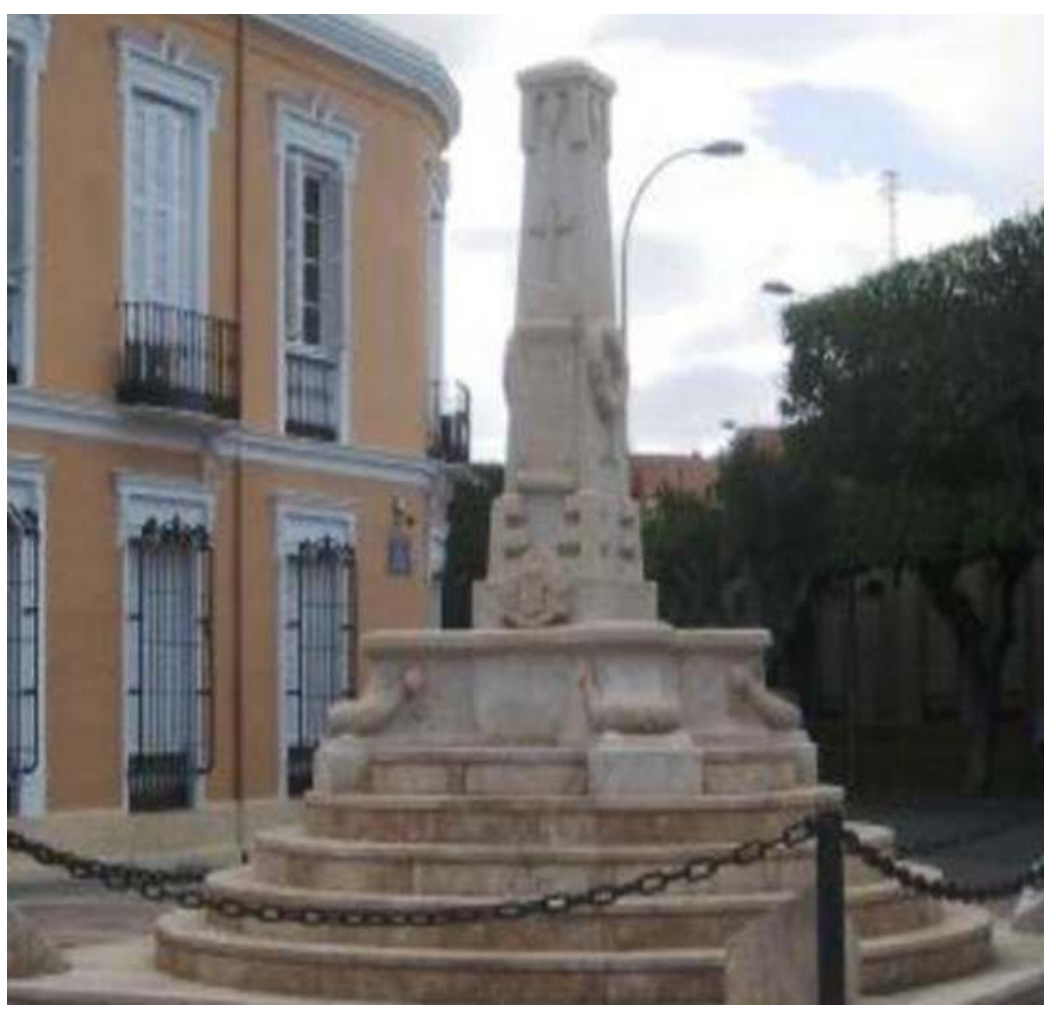

Source : Galerie photographique personnelle

\section{Les rues de Ceuta et Melilla : des agents urbains du nationalisme}

Depuis la Constitution de 1978, de nombreuses villes espagnoles ont démocratisé leur iconographie et leur toponymie urbaines à travers notamment la construction et l'inauguration de places et de monuments dédiés à ce texte constitutionnel, renouvelant ainsi ce que Jacques Le Goff considère comme la tradition du "document-monument " ${ }^{33}$. Avec le retour à la démocratie, beaucoup de référents historiques à la guerre, au coup d'État ou à la dictature ont été effacés, notamment dans les mairies gouvernées par la gauche, et de ce fait, de nombreuses rues ont changé de nom. Plus tard, le débat sur la justice mémorielle s'est matérialisé avec l'approbation de la Loi sur la Mémoire historique en décembre 2007. L'article 15 de cette loi obligea les administrations publiques à prendre les mesures nécessaires pour retirer les blasons, les insignes, les plaques et l'ensemble des objets ou références commémoratives d'exaltation, personnelle ou collective, du soulèvement militaire, de la guerre civile et/ou de la dictature ${ }^{34}$. Toutefois, malgré de nombreuses avancées, les rues de nombreuses villes espagnoles portent encore le souvenir du coup d'État, des vainqueurs de la Guerre et de la période dictatoriale ${ }^{35}$. À Ceuta par exemple, ville gouvernée depuis 2001 par la droite conservatrice du Parti populaire (PP), les autorités locales n'ont cessé de manifester leur refus du retrait des symboles franquistes, accusant à maintes reprises la gauche de "revanchista ${ }^{36}$. Ainsi, le 13 novembre 2007, Yolanda Bel, porte-parole du pouvoir local, établit un parallélisme 
entre les symboles franquistes et les monuments romains de la ville, affirmant qu'on ne détruira ni les uns ni les autres parce qu'ils sont partie intégrante de l'histoire de

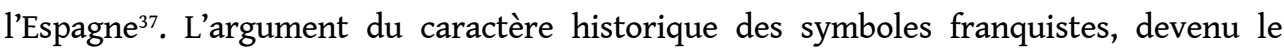
leitmotiv des détracteurs de loi sur la mémoire historique, fut de nouveau utilisé deux ans plus tard par Mabel Deu, ancienne conseillère en charge de la Culture de la ville. Elle employa le même parallélisme: ces symboles coloniaux, franquistes ou phalangistes feraient partie de l'histoire de Ceuta et les effacer reviendrait à effacer les monuments romains $^{38}$. Dans l'actualité, Javier Vaga, dirigeant local du parti de centre droit Ciudadanos, réactive ce discours négationniste lorsqu'il affirme que "todo hay que situarlo en su momento histórico", dédramatisant ainsi l'horreur de la guerre et de la dictature ${ }^{39}$. Ces prises de position des autorités locales sont partagées par un certain nombre d'habitants qui affirment leur étonnement et leur incompréhension face à la remise en cause de la symbolique franquiste. Ces personnes constituent les rares survivants qui attestent cette allégeance sociologique et résiduelle au franquisme qui persiste encore dans ces villes africaines: "Alucino cuando oigo que van a cambiar el nombre de las calles y que van a quitar las imágenes de Franco. Pero todo esto es historia local y nacional, y la historia merece respeto." ${ }^{40}$

Sous les pressions des associations pour la récupération de la mémoire historique et de l'opposition politique locale mais surtout nationale, en avril 2010, la ville de Ceuta a fait un pas en avant en matière de gestion mémorielle. Elle a retiré le nom de Franco du monument dit du «Llano Amarillo » qui rendait hommage aux manœuvres militaires de l'armée d'Afrique quelques jours avant le début de la guerre civile ${ }^{41}$. Ceuta et Melilla ne sont pas les seules villes qui présentent encore des réminiscences de cette époque dans leurs espaces publics, mais il y a une chose qui les rend différentes : elles furent les " adelantadas del Movimiento ", à savoir les berceaux du soulèvement militaire et les deux premières villes où celui-ci triompha. Un fait susceptible d'expliquer la controverse qu'a suscitée, dans ces villes, la loi sur la mémoire historique. Jusqu'en 2010, aucun nom de rue ou de place, aucun monument franquiste n'avait été enlevé, et jusqu'à cette date, les gouvernements locaux n'avaient même pas la volonté de le faire car comme l'affirme bien le maire de Melilla : «La historia está ahí, guste o no guste »"2.

Dans l'actualité, malgré leurs promesses, les maires de ces enclaves espagnoles continuent à ne pas respecter cette loi : Ceuta et Melilla disposent toujours d'un important nombre de symboles franquistes dans leur paysage urbain. Le souvenir du soulèvement militaire et de la dictature se maintient présent dans les noms des rues, comme le montre par exemple la rue "Joaquín García Morato ", l'un des plus grands aviateurs de l'armée nationale. Sur l'entrée du bâtiment de l'hôpital militaire O'Donnell de Ceuta, une plaque commémore toujours des chefs, des officiers et des soldats franquistes morts pendant la guerre civile ${ }^{43}$. Un autre symbole franquiste se trouve à l'intérieur de la caserne Teniente Ruiz, où, sur un blason en plâtre, est gravé le slogan franquiste : «Una, grande y libre $»^{44}$. À l'Institut national du logement, les flèches et le joug présents dans le blason phalangiste accueillent encore le visiteur ${ }^{45}$. 


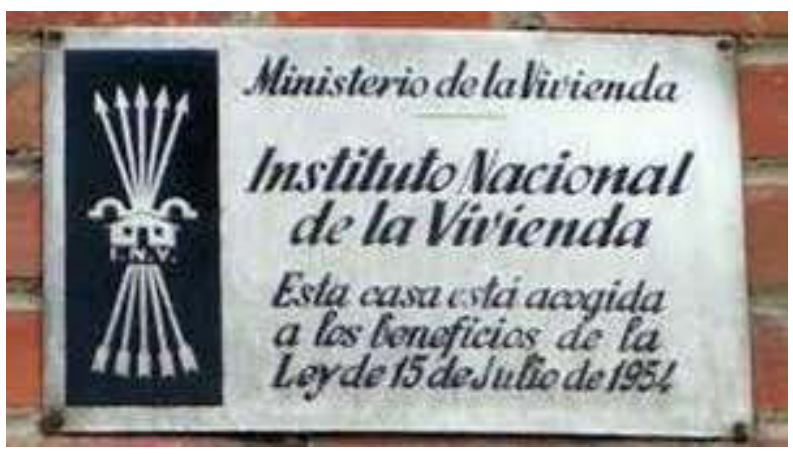

Source : Alicia Fernández García, Vivre ensemble. Conflit et cohabitation à Ceuta et Melilla, Paris, L'Harmattan, 2017, p. 276.

Dans ces enclaves espagnoles, l'« usage public » de la mémoire de la victoire des troupes franquistes sur les bataillons républicains a toujours été très actif et ce, depuis la fin de la guerre civile, comme l'exprime un article de juillet 1941 publié dans le journal El telegrama del Rif qui vante la trace des militaires franquistes dans les noms des rues de Melilla : "Las calles de la ciudad evocan en sus rótulos el paso de los militares invictos, en la Plaza evocadora de España se alza la Victoria." ${ }^{" 46}$ La fin de la guerre d'Espagne donna lieu à de nombreuses initiatives urbanistiques pour dresser toute sorte de monuments (croix, autels, sculptures, etc.), dont la finalité était de promouvoir le souvenir des « morts pour la patrie», faisant ainsi de l'espace urbain un "paysage de sens ${ }^{47}$. Cette politique mémorielle est régie par des organismes tels que le Departamento de Ceremonial y Plástica, la Jefatura Nacional de Bellas Artes ou le Servicio militar de Recuperación del Patrimonio Artístico Nacional, qui veillaient à la sauvegarde et à la transmission d'une série de valeurs et de principes en accord avec le régime ${ }^{48}$. Dans beaucoup de villes espagnoles et dans la plupart des cas sous l'initiative des mairies, on procédait à la construction de ces types de monuments qui, malgré leur variété, possèdent une unité de style et de sens théorisée par les intellectuels phalangistes. À Ceuta et Melilla, la victoire de l'armée nationale contre les Républicains se perpétue encore de nos jours ${ }^{49}$. Citons par exemple le monument à la Victoire, orné du slogan "España, una, grande y libre", les flèches et le joug propres à la Phalange ${ }^{50}$, ou encore l'image de Francisco Franco située à proximité du port ${ }^{51}$. 

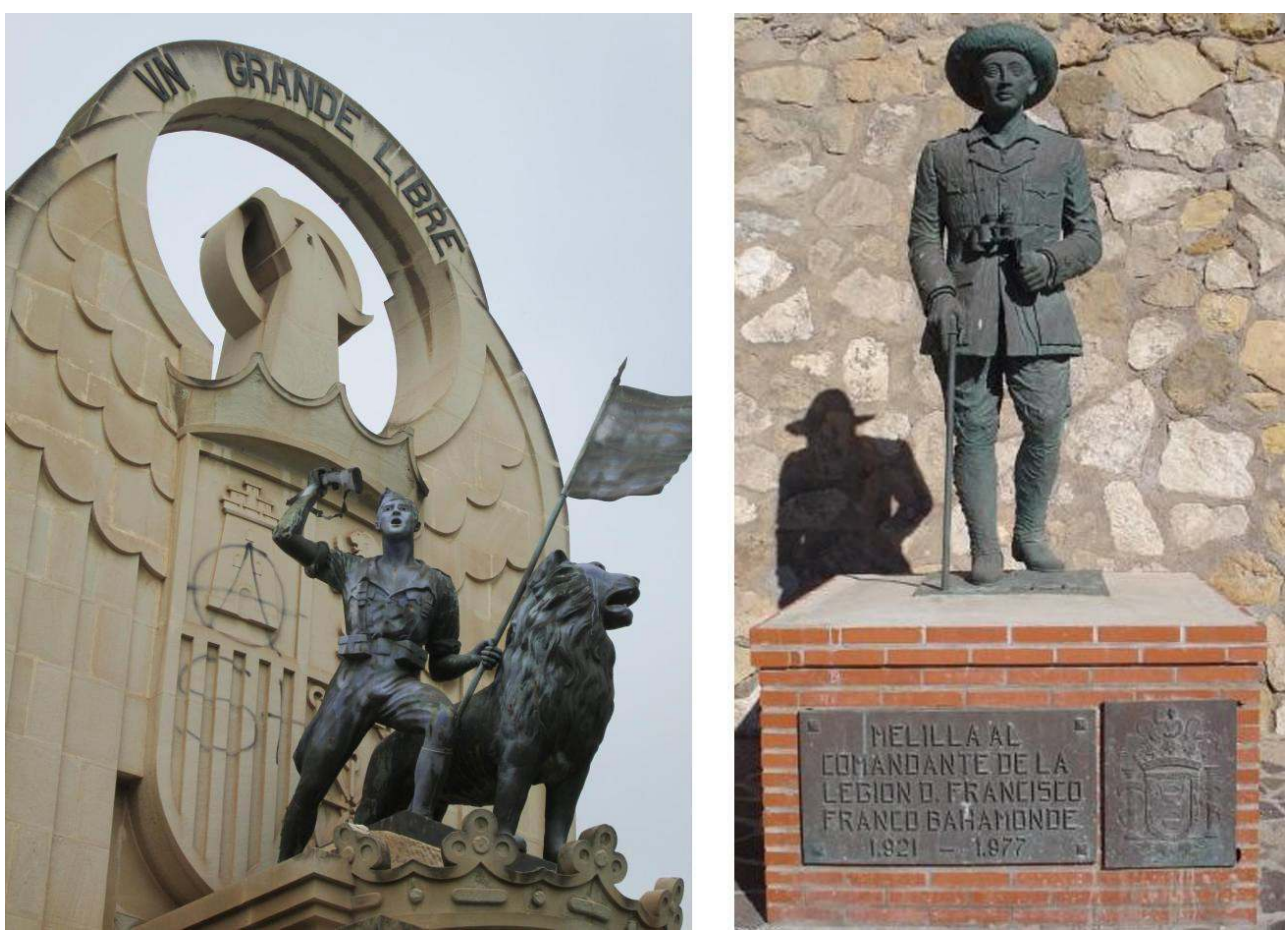

Source : Alicia Fernández García, Vivre ensemble. Conflit et cohabitation à Ceuta et Melilla, Paris, L'Harmattan, 2017, p. 277.

Les arguments en faveur du maintien de la statue de Franco prennent aussi la forme d'un discours soudé qui dénaturalise la figure du dictateur pour la remplacer par l'image du militaire stratège. Joaquín, policier à la retraite, le dit bien lorsqu'il déclare : "cuidadito que Franco no está ahí como dictador sino como jefe militar que no es lo mismo"52. S'appuyer sur la polysémie de la figure de Franco reste la seule voie pour ses défenseurs afin de légitimer son maintien dans l'espace public: "si Franco no está como dictador, entonces no veo donde está el problema" ${ }^{33}$. Il est ainsi présenté non comme un dictateur mais comme une personnalité militaire importante de l'histoire de l'Espagne ${ }^{54}$, voire comme une figure centrale de l'armée d'Afrique ${ }^{55}$.

Les toponymes des rues de Melilla vantent encore l'action des militaires phalangistes et dans l'actualité, les noms de personnalités de la transition démocratique cohabitent avec ceux qui appartiennent au régime franquiste. Ils "partagent» tous le même paysage urbain. Parrmi ces vestiges du ranquisme, on mettra en avant la rue «Milán Astray ${ }^{56}$, fondateur de la Légion et chef de presse et de propagande durant la dictature franquiste ; la rue dédiée au phalangiste « Marina Farinós »; la rue « general José Moscardó » devenu l'icône du soulèvement franquiste grâce à sa défense de l'Alcazar de Tolède face aux troupes républicaines. Certaines plaques commémorent également le séjour de Franco dans la ville (image 5). La permanence de ces vestiges de l'idéologie et de la mythologie franquistes dans le paysage urbain a suscité des débats très intenses entre les abolitionnistes et les défenseurs de la mémoire franquiste dans la ville. Cependant, l'empreinte historique et sociale de ces monuments est non seulement un enjeu symbolique mais aussi électoral, car comme le confie un habitant : «El que toque a Franco en Melilla, pierde las elecciones $"{ }^{57}$. 


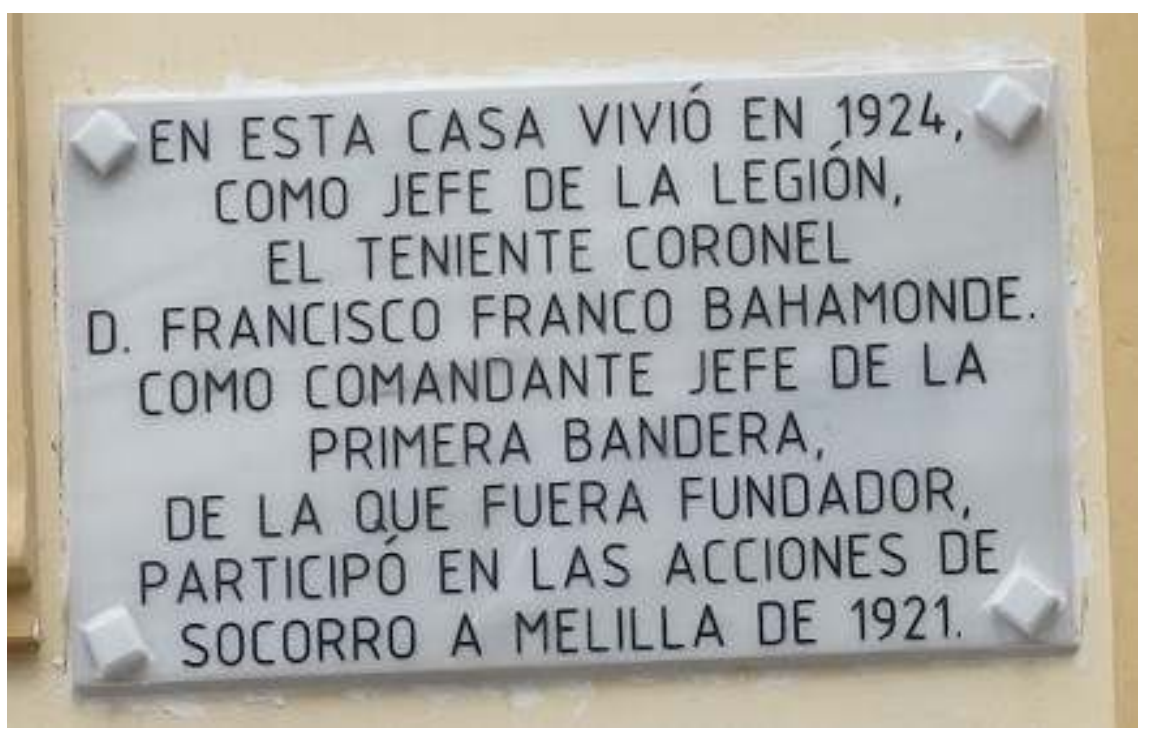

Source : Alicia Fernández García, Vivre ensemble. Conflit et cohabitation à Ceuta et Melilla, Paris, L'Harmattan, 2017, p. 279.

Le 19 février 2001, le journal El País publia un article qui mit en lumière l'existence à Melilla de plus de 56 noms de rues dédiées à des militaires franquistes ${ }^{58}$. Tout un scandale pour une Espagne qui avait entamé une mise à l'écart des années de dictature en l'honneur du droit à la mémoire historique. Melilla demeure aujourd'hui encore la ville espagnole qui présente le plus grand nombre de symboles de la dictature : trois plaques et 57 rues dédiées à des personnages qui participèrent au soulèvement militaire de $1936^{59}$; et dans cette enclave, les vestiges franquistes jouissent d'une sacralisation toute particulière. En 2010, la statue équestre du dictateur qui se trouvait dans la caserne Millán Astray fut retirée, mais pour être réexposée dans la cour centrale d'une entreprise locale, où elle est toujours vénérée par « todos aquellos amantes de la figura del generalísimo » ${ }^{60}$. L'omniprésence de ce legs perpétue l'image de Ceuta et de Melilla comme des «ciudades cuarteles ", ou "villes casernes ", fortement imprégnées de l'héritage franquiste, faisant d'elles, dans l'imaginaire collectif, deux noyaux durs de l'extrême-droite et du nationalisme espagnol. Récemment, le 11 juin 2015, les vestiges du franquisme existants à Melilla firent d'ailleurs la une des médias espagnols lorsqu'une photo polémique montra des agents spéciaux de sécurité affectés à la frontière, enrobés d'un drapeau espagnol et rassemblés autour de la statue de Franco ${ }^{61}$. De plus, à Ceuta, tous les 5 du mois d'août, la patronne de la ville, Notre Dame d'Afrique, fait l'objet d'une procession en étant entourée d'une couverture sur laquelle sont brodés le slogan phalangiste "Una, grande y libre" et le blason franquiste ${ }^{62}$. Dans les sociétés plurielles et multiconfessionnelles de Ceuta et Melilla, dans la mesure où ces monuments proposent une version unique de l'histoire et centrée sur la communauté catholique majoritaire et sur les vainqueurs de la guerre civile et des campagnes coloniales, ils peuvent blesser certaines sensibilités. La présence de ces symboles de l'héritage franquiste suscite souvent une attitude conformiste qui traduit l'existence d'un « franquisme ordinaire ». Les habitants se disent indifférents à la présence de ces symboles et avouent s'être habitués à vivre avec eux : "por mí que quiten todo esto pero vamos que no me molesta" ${ }^{63}$. La même banalisation de la figure du 
dictateur est perçue par un autre enquêté qui affirme : "Ver la imagen de Franco expuesta en la calle es para mí algo normal" ${ }^{64}$.

Finalement, à Ceuta, la nomination du nouveau complexe sportif a aussi été le sujet d'une controverse mémorielle depuis que Fátima Hamed, dirigeante du parti local PDyC (Parti pour la démocratie et la citoyenneté), a proposé de commémorer la mémoire de « Nayim» (Mohamed Ali Amar), l'un des joueurs de football les plus connus de Ceuta. Dans son discours, elle revint sur cette amnésie mémorielle à l'égard du joueur, qui illustrerait selon elle la marginalisation de la population musulmane de l'histoire et de la mémoire de la ville. Elle rappelle que dans trois villes d'Aragon, des rues portent le nom de ce joueur tandis qu'il n'a pas encore obtenu cette reconnaissance à Ceuta, qui est pourtant sa ville natale ${ }^{65}$. Pour les opposants à cet hommage, le centre devrait porter le nom plus «consensuel» d'Emilio Cózar, ex-dirigeant de la fédération de football. Finalement, l'ensemble de ces exemples montre bien que malgré la pression de certains habitants et des associations pour la récupération de la mémoire historique, pour qui ces symboles ne sont que la preuve d'un anachronisme, les maires conservateurs des villes ont délégitimé ces pétitions au nom de l'héritage historique laissé par ces personnalités. Ces faits traduisent le poids du nationalisme espagnol combatif qui demeure aujourd'hui encore imprégné du legs franquiste. Compte tenu de cette "nostalgie nationalecatholique » véhiculée par le culte urbain d'un Âge d'or (les guerres d'Afrique) et d'un franquisme idéalisé, il est assez aisé de comprendre qu'il demeure difficile pour tout une partie de la population de ces villes, et notamment pour les Espagnols d'origine marocaine, de s'identifier à ces symboles ${ }^{66}$.

\section{Mémoire et nationalisme : le passé du présent}

\section{Le calendrier mémoriel, outil de promotion d'une histoire officielle}

Dans la construction d'une mémoire collective, le calendrier commémoratif et festif s'avère être un outil d'une importance capitale qui permet de mettre en avant les moments phares de l'existence collective et qui diffuse des valeurs chères voire mémorables, aux habitants ${ }^{67}$. À Ceuta et Melilla, la critique de ceux que l'on présente péjorativement comme des «Espagnols de convenance » est bien enracinée et influence souvent les propositions mémorielles. De ce fait, lorsque le parti Caballas de Ceuta dirigé par Mohamed Ali, a proposé de ne pas passer au lundi le jour de l'hispanité qui en 2014 tomba un dimanche, afin de pouvoir faire de l'Aïd El-Firt, la rupture du jeûne du Ramadan, un jour férié, cette demande fut interprétée comme l'illustration du faible patriotisme des musulmans et de leur hispanité de façade ${ }^{68}$. Le PP critiqua cette proposition en mettant en question l'“españolidad" de ce groupe politique ${ }^{69}$. Malgré le scandale suscité, la proposition de Mohamed Ali n'avait rien de nouveau car en septembre 2009, on avait déjà accordé de ne pas passer au lundi la fête du dimanche 15 août consacrée à Notre-Dame de l'Assomption, et de déclarer à sa place, comme jour férié, la Pâque du Sacrifice islamique ou Aïd El-Kebir. De même, en 2010, les autorités ont donné leur accord pour faire de la Journée de l'autonomie (2 de septembre), un jour ouvrable, afin de maintenir dans le calendrier local cette fête musulmane ${ }^{70}$. Des propositions considérées par certains comme la preuve que les musulmans disposent à Ceuta d'un espace commémoratif assez important qui pourrait mettre en cause sa culture chrétienne et son hispanitér1. 
23 À Melilla, ces jours fériés sont souvent teintés d'un patriotisme radical et xénophobe. Ce fut par exemple le cas du 12 octobre 2011, jour de l'hispanité, lorsque la Phalange espagnole se déplaça dans cette ville pour exprimer la défense de ces places africaines contre "las agresiones verbales y no verbales que han sufrido por parte de Marruecos"72. Une autre festivité propice à l'expression du nationalisme espagnol est la célébration de la Journée de la ville (journée de l'autonomie) ${ }^{73}$. À Melilla, ce jour de fête est fixé au 17 septembre, date très symbolique dans l'histoire locale, car il s'agit du jour de l'arrivée des troupes du " conquérant » Don Pedro de Estopiñán. Si cette date fit rentrer Melilla dans l'histoire de l'Espagne, elle fut aussi le début des années de guerres et de conflits contre les voisins marocains. Lors de cette célébration, on rend hommage à la figure de Don Pedro de Estopiñán en posant une couronne de laurier sur la tête de sa statue en signe de représentation mythologique de la victoire des Espagnols sur les tribus rifaines. Cette festivité se déroule en présence des autorités civile et militaire qui assistent à la messe, avant un hommage au drapeau national et un défilé de l'armée, illustrant bien cette synthèse religieuse et militaire des célébrations locales.

Le choix de la date est aussi un sujet de controverse : pour le parti Coalition pour Melilla (CpM) dirigé par Mustafa Aberchan, la commémoration d'un personnage, don Pedro de Estopinán, responsable de la mort de nombreux Rifains voisins dans les jours qui suivirent son arrivée, constitue une provocation à l'égard de la communauté d'origine marocaine. Très sensibles à l'histoire locale de la ville, les dirigeants de ce parti ont proposé, à plusieurs reprises, un changement de date : célébrer le Jour de Melilla non pas le 17 septembre, mais le 13 mars, jour où la ville approuva son statut d'autonomie actuel ${ }^{74}$ . Une date plus inclusive à laquelle s'oppose le parti au pouvoir (PP). Son porte-parole Daniel Consea a en effet refusé cette proposition à cause des "nombreuses limites » et « problèmes » du texte autonomique. Ce raisonnement s'apparente plutôt à une excuse car il oublie ainsi que le texte de la Constitution espagnole de 1978 est souvent l'objet de critiques, sans que cela n'empêche les Espagnols de fêter son approbation le 6 décembre (jour de la Constitution).

Dans ces débats sur l'adéquation du calendrier mémoriel des villes à leur réalité sociale, il faut revenir sur ceux suscités par la célébration du jour de Ceuta, le 2 septembre. Dans l'histoire de la ville, cette date fait référence à la conquête portugaise après une journée de lutte ${ }^{75}$. Le souvenir du massacre de la population musulmane mais aussi juive par les troupes portugaises, suscite le malaise de certains habitants. Une attitude soutenue par des leaders politiques locaux tels que Manuel Hernández (PSOE), pour qui cette date symbolise l'assassinat d'une grande partie de la population autochtone ; Fátima Hamed $(\mathrm{MDyC})$ parle d'une «bataille sanguinaire où la population autochtone, juive et musulmane perdit la vie »; et le dirigeant local de Ciudadanos, Javier Varga, qualifie d'erreur le refus du PP quant au changement de cette date ${ }^{76}$. C'est en s'appuyant sur l'argument de l'“españolidad" comme sentiment qui unit tous les habitants que le parti Caballas propose de transférer cette festivité au 13 février, récupérant ainsi le jour très symbolique du 13 février 1640 où les habitants de Ceuta décidèrent de rester sous la couronne espagnole. Ce changement serait justifié car "la hispanidad es el valor esencial de nuestra ciudad, el que nos une y por consiguiente, el que merece ser reconocido"77.

Ainsi, chaque année, l'élaboration du calendrier des commémorations officielles des villes est devenue un sujet de controverse, du fait du capital symbolique qu'il contient et de sa grande importance comme $"$ outil de pouvoir $»^{78}$. Ce que révèle de manière sous-jacente une telle polémique c'est l'existence de deux visions mémorielles opposées et 
irréconciliables entre les deux communautés majoritaires des villes, à savoir celle des Espagnols d'origine péninsulaire et de confession catholique, et celle des Espagnols d'origine marocaine et de confession musulmane. À ce sujet, le parti Caballas de Ceuta a qualifié "d'impensable » pour la cohabitation des différentes communautés, de ne pas faire de la Pâque du Sacrifice et de la fin du Ramadan deux jours fériés. Si la première a été retenue, comme c'est le cas depuis 2010, la fin du Ramadan ne constitue pas encore une fête locale ${ }^{79}$. L'ensemble de ces exemples montrent bien que la sélection des dates des commémorations et des jours fériés constitue un enjeu politique et social qui traduit les rapports de pouvoir entre les communautés au sein de ces villes.

\section{Les cérémonies militaires et l'entretien de la mémoire nationaliste}

27 Les cérémonies militaires jouissent également d'une grande importance à Ceuta et Melilla. Presque chaque mois, on dénombre une célébration d'acte militaire, ou religieux et militaire à la fois, preuve du rapport étroit entre ces deux pouvoirs, et de la volonté des forces armées de célébrer leur présence historique et de perpétuer leur influence sociale. L'importance de l'armée est telle que le journal $E l$ Faro consacre chaque année dans son annuaire des villes, une rubrique sur les événements militaires annuels intitulée "Resumen del año militar". Quelques pages sont également réservées à la gloire des gouverneurs et des commandants militaires passés, où l'on présente leurs biographies, leur attachement aux villes et leur dévouement dans la défense de leur hispanité. Ces bilans de "l'année militaire» mettent en exergue le dynamisme des armées des villes ainsi que leur reconnaissance sociale.

À Ceuta, l'imbrication entre les forces armées, notamment la Légion, et la ville est très forte et vantée par son maire qui proclame: "la estrecha vinculación entre ambas insitituciones"80. Une telle symbiose explique la nomination en 2010 de Ceuta comme "légionnaire d'honneur ", une distinction réservée exclusivement aux personnes, mais comme le révèle bien un dicton populaire : "el caso de Ceuta y la Legión es especial" ${ }^{11}$. Le calendrier mémoriel des villes déborde d'hommages rendus à des chefs militaires, on citera à ce sujet, l'hommage au lieutenant des troupes "Regulares", González Tablas, mort au combat pendant les années du Protectorat ${ }^{82}$, et l'hommage rendu au lieutenant Jacinto Ruiz Mendoza, mort contre les troupes françaises. D'autres dirigeants militaires jouissent également d'une distinction dans l'espace public, où une statue ou un buste les glorifie et les immortalise, c'est le cas par exemple du portrait du lieutenant Mario Emilio Muñoz Diaz, membre de l'armée franquiste.

29 À Melilla, il existe un hommage rendu aux héros d'Alcántara (régiment de chasseurs 14) pour leur participation à la bataille d'Anoual et d'autres hommages sont également rendus au caporal Noval, mort dans la campagne de 1909 contre le Maroc ${ }^{83}$. Ces personnalités sont présentées comme des " héros " locaux et considérées comme des sauveurs de la patrie, comme il apparaît clairement dans les discours des autorités ou dans les journaux, où se succèdent les champs sémantiques de la vénération et la glorification: "héroe de Regulares, el ínclito teniente coronel González Tablas" ${ }^{44}$, "héroe Jacinto Ruiz, el Immortal africano" 85 , "héroe olvidado y después enaltecido", "hijo tan digno" 86, "héroes y mártires de la campaña" ${ }^{87}$, et dont les prouesses sont présentées comme la plus grande "expresión de heroicidad" ${ }^{88}$. Des discours chargés d'une forte rhétorique nationaliste qui opèrent une pleine identification entre d'un côté, patriotisme et nationalisme d'État et de l'autre, défense militaire et foi catholique. De même, ces actes 
militaires se déroulent souvent en présence des autorités civiles de la ville, et sont précédés d'une messe afin d'honorer le personnage mais aussi de perpétuer l'attachement à la foi catholique des membres de l'armée ${ }^{89}$. Un exemple clair de cette symbiose entre les origines, la foi religieuse et le monde militaire est observable dans l'hommage au lieutenant Ruiz : "el teniente Ruiz fue un héroe nacido en Ceuta, bautizado en la iglesia de Los Remedios y miembro del Regimiento Permanente de la ciudad" ${ }^{90}$. Cette association entre religion, État et armée apparaît comme l'essence historique du nationalisme espagnol conçu dans ces villes. De même, le dynamisme de ces cérémonies ainsi que leur nombre cherchent à banaliser le nationalisme espagnol et à légitimer l'ordre établi ${ }^{91}$.

Une autre cérémonie vécue dans la ville avec une énorme ferveur patriotique est la célébration du soulèvement populaire du 2 mai 1808 contre les troupes napoléoniennes. Ce jour constitue le symbole par excellence de l'union nationale et du patriotisme. À Ceuta, ces célébrations du 2 mai sont considérées comme faisant partie de l'idiosyncrasie de la ville : "una tradición arraigada en la ciudad"92. La portée de cette journée de défense de la patrie contre l'envahisseur étranger est réactualisée dans ces villes qui se sentent menacées par le voisin marocain. Les actes qui se succèdent sont considérés comme étant "necesarios y dotados de un carácter emotivo" "93, ou encore comme des témoignages "cargados de un sentimiento patriótico muy necesario"94. Les médias et les discours prononcés font de la défense patriotique un acte d'héroïsme et présentent ces soldats morts au combat comme les libérateurs de la patrie: "Se trata de una cita con el heroismo, el de tantos hombres que dieron su vida por España y por una sociedad mejor". La presse locale, avec ses titres accrocheurs, participe à son tour à la sacralisation de l'armée tel que le manifeste cet article intitulé « El día en el que la Legión salvó a Melilla » ${ }^{95}$. Cette héroïcité propre aux soldats espagnols contraste avec le traitement mémoriel reçu, par exemple, par le lieutenant Mohamed Ben Mizzian ${ }^{96}$, chef des troupes Regulares indígenas. Si sa description a fait l'objet d'une chronique publiée dans le journal El Faro de Ceut $a^{97}$, elle est toutefois loin de la glorification propre aux généraux espagnols.

31 Enfin, une dernière célébration militaire très chère aux villes est la journée consacrée aux Forces Armées, connue sous les sigles DIFAS. Cette festivité qui remonte à l'année 1978 se veut un hommage aux armées et l'expression de leur rapprochement avec la société. Cet événement est toujours très attendu. L'un des moments les plus symboliques est la levée du drapeau espagnol face au monument aux soldats morts durant la guerre d'Afrique $(1859-1860)^{98}$, ce qui remet ainsi en question le caractère conciliateur et consensuel poursuivi. L'émotion que cela suscite exprime l'attachement de la société des villes aussi bien à la patrie espagnole symbolisée dans ce drapeau, qu'au corps militaire. Lorsque Antonio, un habitant de Ceuta, m'expliqua le déroulement de cet acte, il avoua le patriotisme qu'il ressent lors d'un tel événement : "hay que tener muy duro el corazón y muy fría o vacía de todo pensamiento patrio la mente para no sentir un nudo en la garganta y un cosquilleo en la piel"99. Cette considération et ce respect pour l'armée s'applique aussi pour les forces de l'ordre. Des articles dans la presse locale, tels que "La policía local es un cuerpo muy querido en Ceuta" 100 , ou la distinction "Medalla de oro " octroyée à la Police de Melilla ${ }^{101}$ véhiculent bien la considération et l'estime des habitants à l'égard des forces de l'ordre et sont révélateurs de la propagande nationaliste des médias. 


\section{Conclusion}

Quelles sont les représentations sociales du nationalisme espagnol dans le paysage urbain de Ceuta et Melilla ? Pour répondre à cette question, il faut tout d'abord souligner que dans la construction du nationalisme espagnol, les discours officiels, l'invention de traditions, la célébration de cérémonies ainsi que les symboles, les monuments et les lieux de mémoire ont été essentiels à la création et à l'entretien d'un imaginaire national. Ainsi, une approche du nationalisme espagnol à travers ses symboles et ses lieux de mémoire permet de constater à quel point la reconstruction historique de ces deux villes est devenue une priorité politique locale. On cherche à ancrer une souveraineté espagnole, à vanter un patriotisme et à dater des origines latines le plus loin possible dans l'histoire. Le pouvoir politique a très bien compris la valeur symbolique du patrimoine qui, dans ces villes, est le résultat d'une identification exclusive à l'Antiquité gréco-romaine et à la civilisation occidentale. On trouve une iconographie nationaliste, présente à travers les sculptures, les noms des rues et les plaques commémoratives, qui participe à l'entretien d'un nationalisme espagnol fondé sur la transmission d'une mémoire sélective, à savoir celle des vainqueurs, et sur une forme de négationnisme historique à l'égard de l'apport du voisin marocain et de la composante musulmane des sociétés de ces villes. En effet, les quelques allusions faites à ces voisins marocains reprennent le plus souvent la dichotomie stéréotypée entre civilisation chrétienne et barbarie maure, largement répandue dans les discours patriotiques propres aux guerres d'Afrique.

Le calendrier des commémorations et des célébrations s'avère être également un outil d'importance capitale dans la construction du nationalisme à Ceuta et Melilla. Les fêtes locales (17 septembre à Melilla et 2 septembre à Ceuta), sont souvent teintées d'un patriotisme radical voire guerrier, dans la mesure où avec la commémoration de leur découverte par les Portugais (Ceuta, 1415) et par les Espagnols (Melilla, 1497), on rend aussi hommage aux années de massacre, de guerres et de conflits contre les voisins marocains. Un calendrier mémoriel qui déborde également d'hommages rendus à des chefs militaires, hissés au rang de héros locaux et considérés comme des sauveurs de la patrie. La presse locale participe aussi à l'entretien du nationalisme espagnol. Dans les pages des journaux des villes se succèdent des articles, des reportages, des chroniques à fort caractère patriotique qui exaltent une bataille, un événement militaire ou religieux ou un personnage censé incarner la défense nationale des villes face à un ennemi historique, à savoir le voisin marocain.

De même, cette politique de nationalisation liée aux lieux de mémoire est observable à travers l'instrumentalisation de la toponymie des rues, dont les noms vantent encore la victoire des soldats espagnols contre les voisins rifains et celle des troupes franquistes sur les républicains. Un décalage par rapport à une Espagne qui se veut démocratique et qui ouvre de plus en plus le débat sur la justice mémorielle des victimes du franquisme et de la guerre civile. Ainsi, l'une des difficultés auxquelles fait aujourd'hui face le nationalisme espagnol à Ceuta et Melilla est justement de parvenir à se détacher de cet héritage à la fois colonial et dictatorial qui nourrit un nationalisme espagnol militarisé réduisant ces enclaves espagnoles à leur rôle de «bastions du franquisme». Ce travail de reconstruction d'une mémoire nationale ne fait d'ailleurs pas consensus dans les villes. Il engendre de nombreux conflits politiques et des représentations sociales distinctes en fonction des communautés, montrant bien que le processus de création et de diffusion 
d'une mémoire nationale donne lieu à des luttes de pouvoir et demeure un enjeu historique, politique et social contesté.

\section{NOTES}

1. Stéphane Michonneau définit la politique de la mémoire comme « un processus social qui a pour objectif de délimiter un passé et de le construire comme le signe distinctif d'un groupe social particulier ». Cf. Barcelona: memoria i identitat. Monuments, commemoracions i mites, Vic, Eumo Editorial, 2002, p. 425.

2. David Parra Montserrat, “¿Reescribir la historia patria?: diversas visiones de España del africanismo franquista", in Ismael Sanz et Fernán Archilés (dir.), La nación de los españoles: discursos y prácticas del nacionalismo español en la época contemporánea, Valencia, Universidad de Valencia, 2012, p. 225.

3. Marta Lería Mosquera, "La historia de Ceuta a través de las esculturas de la ciudad", Cuadernos del Archivo Municipal de Ceuta, n¹8, 2009, p. 325-341.

4. L'un des deux Hercules est situé près du port de Ceuta, et l'autre à l'extrémité de la Place de la Constitution. Tous les deux dominent les eaux du détroit. Ils sont l'œuvre de l'artiste Serrán Pagán.

5. Sous le buste de Platón on peut lire: "El filósofo griego Platón mencionaba 'los pilares de Hercules', Calpe (Gibraltar) y Abyla (Ceuta), en sus libros 'criticas' y 'timeo' refiriéndose a la atlántida, la isla hundida por un maremoto. En su 'Timoteo', Platón decía: 'en aquella época se podía atravesar aquel océano dado que había una isla delante de las columnas de Hércules. En dicha isla, llamada Atlántida, había surgido una confederación de reyes que gobernaba sobre ella". Sous la scuplture de Pompinio Mela, il est écrit : "Más adelante hay una montaña alta frente a otra opuesta de Hispania; a aquella llaman Abyla, a esta Calpe; a una y otra columna de Hércules. Respecto a este nombre se dice que fue el mismo Hércules quien separó ambas cumbres, antes unidas por una cadena montañosa continua, que por ello el océano, hasta entonces contenido por esta mole montañosa, inundó el espacio que hoy ocupa."

6. Le géographe Al-Idrisi né à Ceuta en 1099 réalise dans son ouvrage La Geografía de Occidente, une description de sa ville natale.

7. José Garcia Cosio, Ceuta. Historia, presente y futuro, Granada, Godino, 1988, p. 20.

8. Discours du député Francisco Márquez (PP) à l'Assemblée de la ville, 23 septembre 2014, [ http://popularesceuta.es/index.php/actualidad/80-articulos/750-art-inter-fmarq-2], consulté le 2 octobre 2015.

9. “21 agosto 1415, una fecha histórica”, El Pueblo de Ceuta, 21 août 2015.

10. Marta Lería Mosquera, op. cit., 2009, p. 334.

11. “Melilla, secretos del modernismo", El País, 16 décembre 2006.

12. Guide d'information touristique "Melilla modernista", année 2015.

13. Alicia Fernández García, Vivre ensemble. Conflit et cohabitation à Ceuta et Melilla, Paris, L'Harmattan, 2017, p. 271-272.

14. "La ciudad española situada en el norte de África ofrece al visitante más de 500 obras arquitectónicas catalogadas de estilo modernista", [http://www.nationalgeographic.com.es/ viajes/grandes-reportajes/ruta-del-modernismo-melilla_10673], consulté le 10 mai 2017.

15. Alicia Fernández García, op. cit., 2017, p. 272. 
16. Julia Rey Pérez et Víctor Hernández Santaolalla, "El hito urbano como mensaje. Arquitectura, comunicación y valores comparativos”, Questiones publicitarias, №18, 2013, p. 111-125.

17. Christian Delporte, Laurent Gervereau et Denis Maréchal (dir.), Quelle est la place des images en histoire?, Paris, Nouveau monde éditions, 2008.

18. Javier Marcos Arévalo, "La tradición, el patrimonio y la identidad", Revista de estudios extremeños, vol. 60, nํ 3, 2004, p. 929.

19. Julia Rey Pérez et Víctor Hernández Santaolalla, op. cit., 2013, p. 123.

20. Marc Augé, Les non-lieux. Introduction à une anthropologie de la surmodernité, Paris, Seuil, 1992, p. 100 et 119 .

21. Pierre Nora (dir.), Les lieux de mémoire, Paris, Gallimard, vol. I, 1997.

22. El monumento fue inaugurado el 4 de mayo de 1895.

23. Marie Claude Lecuyer et Carlos Serrrano, La guerre d'Afrique et ses répercussions sur l'Espagne (1859-1909), Paris, Presses universitaires de France, 1976.

24. Joaquín Álvarez Cruz, "Monumento a los caídos en la guerra de África de 1859-1860", Cuadernos del Archivo Municipal de Ceuta, nำ13, 2004, p. 153-176.

25. Juan Francisco Fuentes, El fin del Antiguo Régimen (1808-1868). Política y sociedad, Madrid, Síntesis, 2007, p. 216.

26. Le sculpteur choisi pour la construction de ce monument achevé au mois de juillet 1893 fut Antonio Susillo, connu pour sa statue d'un patriotisme exorbitant consacrée au capitaine Luis Daoiz, militaire espagnol qui participa activement au soulèvement du peuple de Madrid contre les troupes napoléoniennes le 2 mai 1808. Avec son collègue Velarde, il est devenu l'un des héros de la guerre d'Indépendance (1808-1814).

27. Joaquín Àlvarez Cruz, op. cit., 2004, p. 162.

28. Xosé Manoel, Nuñez Seixas, "La nación contra sí misma: nacionalismos españoles durante la Guerra civil (1936-39)”, in Carlos Taibo (dir.), Nacionalismo español. Esencia, memorias e instituciones, Madrid, Catarata, 2007, p. 75-111.

29. Miguel Ballenilla, "Panteón de los héroes de las campañas. En el cementerio de la Purísima Concepción de Melilla", [http://www.historiadeltiempopresente.com/web/ documentosDescargables/Articulos/RT16.pdf], consulté le 30 octobre 2015.

30. Luis Castro, Héroes y Caídos. Políticas de la memoria en la España contemporánea, Madrid, Catarata, 2007, p. 318.

31. Ce monument se trouve depuis 2013 sur la place Pedro Segura qui a été totalement aménagée pour l'accueillir. Avant, il se trouvait dans la caserne du régiment de cavalerie Alcántara.

32. Rosa Soto, "Los héroes de Taxdirt", El Faro de Melilla, 4 novembre 2017.

33. Jacques Le Goff, "Documento/Monumento", Enciclopedia Torino, Einaudi, 1978, vol. 5, p. 38-47.

34. Loi 52/2007, du 26 décembre 2007, [ http://www.boe.es/diario_boe/txt.php?id=BOEA-2007-22296], consulté le 2 novembre 2015.

35. Paloma Aguilar Fernández, Políticas de la memoria y memorias de la política, Madrid, Alianza, 2008, p. 41-42.

36. “Rubiales y la Guerra Civil calientan el pleno", El País, 28 septiembre de 2006.

37. "El gobierno de Ceuta no quitará los símbolos franquistas", 20 minutos, 14 octobre 2007.

38. "La última estatua de Franco se resiste a morir", La información.com [en ligne], 4 août 2010.

39. "Áspero debate a cuenta del cumplimiento de la Ley de Memoria histórica", Ceuta actualidad [en ligne], 27 janvier 2016.

40. Entretien avec Sandra, professeure, Melilla, 24 avril 2015.

41. "Ceuta elimina su última referencia al franquismo", ABC, 7 avril 2010.

42. "Imbroda dice que fue por respeto a la ceremonia íntima de Sanjurjo" El Periódico, 22 avril 2017.

43. Ce centre hospitalier se trouve sur l'avenue Doctor Marañón à Ceuta. 
44. La caserne Teniente Ruiz se situe dans la rue Cortadura del Valle Pozo Rayo. Le blason en question se trouve à la hauteur de l'escalier gauche menant aux bureaux.

45. Plaque située sur la façade de l'Institut pour le logement des forces armées, av. San Juan de Dios, $\mathrm{n}^{\circ} 6$.

46. “A la gloria de la Victoria", El telegrama del Rif, 22 juillet 1941.

47. Eviatar Zerubavel, Social Mindescapes. An invitation to congnitive sociology, Harvard, Harvard University Press, 1999, p. 20-28.

48. Luis Castro, op. cit., 2008, p. 146-147.

49. Montserrat Duch Plana, "Toponimia franquista en democracia", in Carlos Forcadell, Carmen Frías et Carmen, Rújula, Usos políticos de la historia, Zaragoza, Universidad de Zaragoza, vol. I, 2002, p. $377-390$

50. Monument situé sur la place nommée Héroes de España, Melilla.

51. Cette statue est placée sur l'avenue General Macías, en face du port. Sur cette plaque commémorative on peut lire: "Melilla al comandante de la legión Don Francisco Franco Bahamonte, 1921-1977".

52. Entrevista con Joaquín, miembro del centro Hijos de Melilla, 27 avril 2015.

53. Entretien avec Natalia, militante du parti Populares en Libertad (PPL), Melilla, 27 avril 2015.

54. Entretien avec Marta, professeure de Melilla, 25 avril 2015.

55. Entretien avec Juan Carlos, professeur de philosophie, Melilla, 29 avril 2015.

56. Intéressé par la création d'un corps de volontaires étrangers sur le modèle de la Légion étrangère française, Millan Astray se déplaça en Algérie afin d'y étudier son fonctionnement. À son retour, le 28 janvier 1920, il créa la Légion sous les ordres du ministre de la guerre, le général José Villalba Riquelme, pour créer ensuite le corps Tercio de Extranjeros. C'est à lui que l'on doit le cri à forte connotation guerrière " $¡ V i v a$ la muerte!”.

57. "El monumento franquista de Melilla", [http://elalminardemelilla.com/2014/04/09/elmonumento-franquista-de-melilla/], consulté le 25 octobre 2015.

58. Carlos E. Cué, "Defensa se niega a retirar símbolos franquistas de Melilla”, El País, 19 février 2001.

59. "Melilla defiende por vía judicial la última estatua de Franco", El País, 23 août 2017; "Eduardo Ranz: Melilla, es la ciudad con mayor cantidad de símbolos franquistas", Melilla Hoy, 14 mars 2015.

60. "Melilla, último bastión del franquismo", Público, 8 janvier 2014

61. Pedro Aguedas, "Los antidisturbios de la Guardia Civil de Melilla se fotografían ante la estatua de Franco", El Periódico, 11 juin 2015.

62. "La Virgen de África luce un manto con el escudo de la dictadura franquista en los actos oficiales de las fiestas", Ceutaactualidad [en ligne], 5 août 2015.

63. Entretien avec Antonio, étudiant, 23 ans, 26 avril 2015.

64. Entretien avec Mustafá Akalay, Melilla, 27 avril 2015.

65. “¿Debe llamarse Mohamed Ali Amar o Emilio Cozar el nuevo campo de fútbol de Ceuta?”, El Mundo, 17 février 2015.

66. Xosé Manoel, Númez Seixas, op. cit., 2008, p. 164-165.

67. Jacques Le Goff, Histoire et mémoire, Paris, Gallimard, 1988, p. 57-59.

68. "El PP no cambiará el festivo de la Hispanidad", El Faro de Ceuta, 14 septembre 2013.

69. “UPyD y PSOE valoran la propuesta de calendario laboral”, El Faro de Ceuta, 13 septembre 2013.

70. “Caballas propone incluir en el calendario de 2014 la Pascua de final de Ramadán”, Ceuta al día [en ligne], 12 septembre 2013.

71. "La presión de nuestro islam", El País, 12 septembre 2005. Sur les revendications des mimorités à Ceuta, lire Carlos Rontomé, Ceuta: convivencia y conflicto en una sociedad multiétnica, Ceuta, UNED-IEC, 2012, p. 249-278. 
72. "La Falange se traslada a Melilla para denunciar las agresiones de Marruecos", Diario crítico [en ligne], 13 octobre 2011. Lire également, “La oposición condena el discurso 'islamófobo' de Falange española", El telegrama de Melilla, 15 octobre 2010.

73. En 1986, le collectif musulman de la ville s'opposa pour la première fois à la célébration de l'événement de sa conquête. Les années suivantes, les représentants de ce collectif s'opposèrent à cet acte avec des termes tels que : «jour gâché », « triste commémoration », " acte institutionnel décaféiné », « triste spectacle ». C'est en 1991 que le maire conservateur Ignacio Vázquez déclara férié ce jour du 17 septembre. Il faut ajouter à ce sujet que lorsque Mustafa Aberchan fut élu à la tête de la ville en 1999, ce maire musulman assista à la messe et procéda à l'offrande à la Vierge, un geste applaudi par la population locale. Toutefois, le fait de ne pas déposer une couronne de laurier sur la tête du conquérant Pedro de Estopinán, entraîna des critiques qui lui valurent le qualificatif de « président peu patriote ».

74. Silvia Perdiguero, "Melilla celebra hoy sus 515 años del inicio de su historia española", El Faro de Melilla, 17 septembre 2012

75. Dominique Lelievre, op. cit., 1988, p. 220.

76. Carmen, Echarri, "El calendario laboral aprobado sin el final de Ramadán como festivo", El Faro de Ceuta, $1^{\text {er }}$ octobre 2015.

77. "Caballas quiere que la Pascua del Sacrificio y el final de Ramadán sean festivos", El Faro de Ceuta, 23 septembre 2015.

78. Mathieu Petithomme, «Mémoire et politique à Chypre du Nord », Cahiers balkaniques, no43, 2015.

79. En mayo 2017, el gobierno local de Juan Vivas (PP) anuncia que el fin del Ramadán será declarado festivo en el calendario escolar para el curso 2017/2018. Sin embargo, esta fiesta musulmana se excluye del calendario laboral ceutí.

80. “Ceuta, primera ciudad que ostenta el título de legionario de honor", El Faro de Ceuta, 30 décembre 2010.

81. Ibid.

82. La mort du lieutenant Santiago González Tablas eut lieu en 1922 pendant le siège de Tazarut dans la zone du protectorat espagnol. Avec lui, le commandant Medina mourut aussi d'une balle dans la tête.

83. "Regulares homenajean al capitán Moreno de Antequera", El Faro de Melilla, 31 mars 2013.

84. "De la cama a las armas", El Faro de Ceuta, 3 mai 2014. Les italiques sont mis en avant par l'auteure.

85. “Jacinto Ruiz, héroe olvidado", El Faro de Ceuta, 4 mai 2014.

86. “Tradición con más de un siglo”, El Faro de Ceuta, 4 mai 2014

87. Ibid.

88. "Homenaje a los héroes de Alcántara en el $92^{\circ}$ aniversario de Annual", El Faro de Melilla, 17 juillet 2013.

89. "Regulares de Ceuta $n^{\circ}$ 54", [http://webcomputing.org/regulares/?p=1729], consulté le 6 novembre 2015 .

90. “Acto en memoria del teniente Ruiz, héroe de la guerra de la Independencia”, El Faro de Ceuta, $1^{\mathrm{er}}$ mai 2014.

91. Pedro, Oliver Olmo, "El nacionalismo del ejército español: límites y retóricas", in Carlos Taibo (dir.), op. cit., 2007, p. 216-217.

92. “Ceuta rinde un año más tributo a su héroe de 1808”, El Faro de Ceuta, 3 mai 2014.

93. Ibid.

94. Antonio Guerra, “Restitución de la dignidad española de 1808”, El Faro de Melilla, 3 mai 2015.

95. $A B C, 20$ janvier 2014. 
96. Suite à l'indépendance du Maroc et à cause de l'oisiveté à laquelle la fin du protectorat avait condamné de nombreux soldats, ce lieutenant s'engagea dans l'armée marocaine oùil devint Maréchal

97. "El teniente general Ben Mizzian y su huella en Regulares", El Faro de Ceuta, 19 janvier 2014.

98. "Unos 1.900 militares desfilan en Melilla por el día de las Fuerzas Armadas", La Vanguardia, 7 juin 2014.

99. Entretien avec Antonio R., retraité, Ceuta, 28 octobre 2014.

100. El Faro de Ceuta, 7 mai 2014.

101. "El Colegio de Abogados concederá la Medalla de Oro a la Jefatura de la Policía Nacional", Melilla Hoy, 6 octobre 2016.

\section{RÉSUMÉS}

Ceuta et Melilla sont deux enclaves espagnoles situées au nord de l'Afrique dont la conquête fut le résultat d'une lutte acharnée contre le voisin marocain. Depuis lors, ces territoires « contestés » sont devenus deux lieux d'affrontement entre deux nationalismes, l'espagnol et le marocain. Cet article se propose d'étudier les représentations sociales du nationalisme espagnol dans le paysage urbain de Ceuta et Melilla ainsi que son marquage territorial. Pour y parvenir, nous étudierons l'instrumentalisation de l'espace urbain de ces enclaves espagnoles à travers la création de lieux de mémoire et l'iconographie nationaliste tout en nous intéressant également à la reconstruction historique du passé de ces villes. Enfin, nous analyserons comment le calendrier mémoriel de ces villes, à savoir les fêtes, les cérémonies et les commémorations, perpétuent la mémoire du nationalisme espagnol.

Ceuta y Melilla son dos enclaves españoles situados en el norte de África cuya conquista fue el resultado de una lucha encarnizada contra el vecino marroquí. Desde entonces, estos territorios "contestados" son lugares de afrontamiento entre dos nacionalismos, el marroquí y el español. Este artículo se propone estudiar las representaciones sociales del nacionalismo español existente en el paisaje urbano de Ceuta y Melilla así como su trazado territorial. Para ello, estudiaremos la instrumentalización del espacio urbano a través de la creación de lugares de memoria y de la iconografía nacionalista propios a estas dos ciudades pero también nos interesaremos en la reconstrucción histórica del pasado de estas dos ciudades. Finalmente, analizaremos cómo el calendario memorial de estas ciudades, es decir, las fiestas, las ceremonias y las conmemoraciones perpetúan la memoria del nacionalismo español.

\section{INDEX}

Mots-clés : paysage urbain, nationalisme, Ceuta et Melilla, lieux de mémoire

Palabras claves : paisaje urbano, nacionalismo, Ceuta y Melilla, lugares de memoria 


\section{AUTEUR}

\section{ALICIA FERNÁNDEZ GARCÍA}

Université Grenoble Alpes (ILCEA4) 